\title{
The implications of interrelationships for decision making processes in companies along the supply chain.
}

\author{
F. E. Coll, A. S. Carrie, U. S. Bititci, \& A. Reid \\ DMEM, University of Strathclyde \\ Glasgow G1 1 XJ, UK \\ Tel: + 44 (0) 1415482588 email: f.e.coll@strath.ac.uk \\ J. H. Trienekens
}

Dept. of Management Studies, University of Wageningen Hollendseweg1, 6706 KN, Wageningen, The Netherlands email: jack.trienekens@alg.bk.wau.nl

\section{H. H. Hvolby}

Dept. of Production, University of Aalborg

Fibigerstrcede 16, Aalborg East, Denmark

Denmark

email:i9hhh@iprod.auc.dk

\begin{abstract}
This paper presents an adapted GRAI grid approach to modelling the decision making processes of vertically related firms in a business network. A framework for assessing case studies is used to model part of the supply chain in three different industries, and identify areas for improving the connectivity between the individual companies. The key factors affecting the effectiveness were found to be opacity of information concerning demand, and delays due to uncoordinated decision making processes in linked firms.
\end{abstract}

\section{Keywords}

Industrial networks, supply chain, coordinated decision making, GRAI grids. 


\section{INTRODUCTION}

Current research into the logistic activities of firms is supplemented by advances in the creation of taxonomies of industrial network models (Moller et al., 98), and investigations into the relational issues which affect networked firms (Elg and Johansson 96). In a 'virtual organisation' a variety of business processes and people collectively engage to fulfil the demand of the ultimate customer. Ownership of processes is not an operational issue. In order for the virtual organisation to work, coordination of the manufacturing planning and control systems (MPC's) is necessary. This paper justifies the existence of interactions between the systems, and goes on to describe them using modified GRAI grids in a variety of industries (the textile, food processing, and consumer electronics industries). The grids and inconsistencies that may act as barriers to the development of the virtual organisation are discussed. The paper concludes that the development of coordinated decision-making is important in allowing an efficient network of companies to operate, and provides a list of key issues for future research.

\section{VERTICALLY LINKED FIRMS AND THE SUPPLY CHAIN}

The concept of the supply chain is a blurred one within the domain of logistics. If interpreted literally, it looks upstream from the perspective of the firm in focus, making it different for each entity concerned. However, this is too exclusive a definition, in that the term encompasses areas such as finished inventory management and their subsequent distribution. Rather, the supply chain acts as a metaphor which is applied to a bundle of inter-related concepts such as materials management, supplier relationships, organisational networks and overall process integration (New, 1996).

This metaphor can be tailored to suit the individual structure of a company, allowing the company to place the emphasis on the elements of the chain it feels are of significance. It simultaneously contributes to the confusion regarding its exact nature. It can be defined as an overall "integrating philosophy to manage the total flow of a distribution channel from supplier to ultimate customer" (Ellram and Cooper 1993).

Implicit within this philosophy are the concepts of:

- purchasing, manufacturing and distribution.

- trading partner relationships.

- relationships within the industrial network.

These necessitate a strategic approach to the management of the supply chain which recognises the implications of interactions between linked activities in all firms. Currently no conclusive proof exists that a relationship cultivated between an individual buyer and supplier will provide benefits exclusive to that relationship- the potential rewards are contingent on the structure of the network within which this relationship is embedded. (New, 1996). 
The overall trend towards developing lasting 'interrelationships' seems set, however, to continue. Interrelationships can be said to occupy the central region of a continuum which is delimited by the notion of transaction-based economic theory of perfect markets on one hand, and fixed hierarchies on the other (Williamson, 1979). The institutionalist approach, allied with contributions from interorganisational theory has been used by the IMP group to develop an 'interaction model' (Hakansson, 1982). This has provided a basis for the development of network theory, thereby providing an insight into the linkages between supplier and customer. While horizontal linkages are concerned with interfirm collaboration on issues such as research and market development, research of coordinated logistics and information flow tends towards an analysis of vertical linkages (Rich and Hines, 1997).

Each case study includes three vertically linked firms forming part of a network. A further common feature is that the final firm is a retail outlet to the consumer.

\subsection{GRAI grids}

The GRAI grid originated from systems theory, and describes the decision making processes within a company in the context of its Production Planning and Control system. The 'decision' system, in conjunction with the 'operating' and 'information' systems forms the Production Management System. (Doumeingts, 1995). The grid provides for the positioning of 'decision centres' (nodes that receive inputs in the form of decisional frames and information, and make resultant frames) according to whether they are 'event' or 'periodic' driven. The grid is hierarchical, ranging from decisions which have far reaching (i.e. strategic) implications with correspondingly long intervals between consecutive reviews, to frequently made decisions in real time (i.e. production). Each decision centre has one or more objectives that are to be achieved by a certain time- the 'horizon'.

Progress is reviewed periodically to ensure that the desired result is achieved. A set of rules exist that is used to ensure the consistency of the model. GRAI grids have typically been used to create a model of the decision making processes in the manufacturing systems of a company, but have also been used to assess the effectiveness of the management structure and information flow (Downey et al. 1989).

\subsection{Coordinated decision making}

A characteristic of the vertically integrated firm is a centralised decision system (DS). The equivalent system envisaged in the extended enterprise is holonic; locally autonomous, but globally connected (O'Neill and Sackett, 1994). This is of relevance in the broader context of networks, where synchronicity of decision making contributes to overall effectiveness, particularly in the case of operations and logistics. Where autonomous DS's are linked, inefficiency results due to decisions in each firm being propagated at different times. (An example would be the case of creating a call-off order twice a week in one firm, which is processed 
weekly by the supplier. This gives rise to a situation where orders are processed more than a week after they were initially sent). Where relevant information is lacking or is delayed, the situation is further exacerbated, giving rise to phenomena such as the Forrester effect (Towill, 1995).

The root cause of these phenomena is the effect of imperfect or delayed information on the supply chain. As outlined above, mismatched decision centres in companies along the chain can contribute to delaying information.

\subsection{Adapting the GRAI grid}

The network is not a vertically integrated organisation- at any one time it consists of separate firms. Therefore a single GRAI grid is not appropriate. Instead some of the existing rules are adapted in order to connect several grids. An example taken from the food processing industry is shown in figure 1.

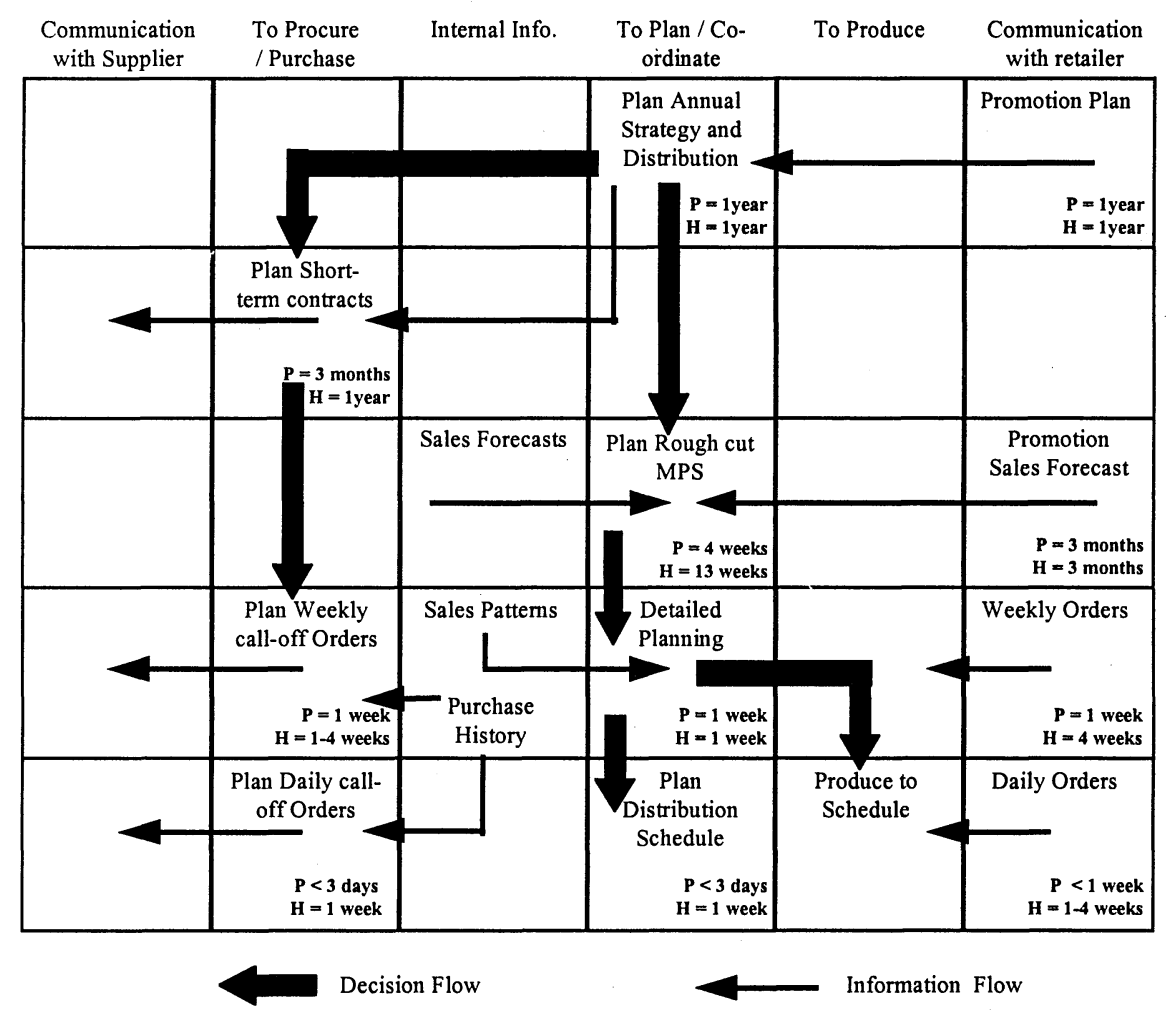

Figure 1: GRAI grid of manufacturer in food processing industry.

- The two information columns at either end of the grid reflect upstream and 
downstream linkages. These linkages can consist of information and decision frames (e.g. in the case of a dominant buyer / supplier relationship). Internal information is a separate column located in the centre of the part of the grid 'owned' by that firm.

- Interfirm communication must consist of flows which connect decision centres with common horizons and periods, and which have similar decision variables.

\section{RESEARCH METHODOLOGY}

The methodology consisted of holding interviews with relevant personnel in the various firms and creating a generic grid consisting of five levels, ranging from strategic to real time production. The functions are still firm specific. The position of the centres in the decision hierarchy is determined by the type of decision, rather than specific horizons or periods (hence these are shown in every cell). A set of questions was agreed on which provided the basis for a semi-structured interview. Each of the three industries provided a case study example of three interrelated decision systems along the supply chain. The fact that interrelationships are assumed to exist is borne out by the fact that all partners in the various industries had been collaborating for a number of years prior to the interviews. The objective of the interview was to create a picture of the decision processes, and then examine them for inconsistencies.

\section{DISCUSSION}

\subsection{Foodstuffs Industry}

Situated in Europe, this comprises of the retailing company, the food-processing factory, and the grower of the foodstuffs. It may be characterised as follows:

- The supply of raw materials is uncertain, due to variables such as weather during growth and harvest, and topological variations. These also affect quality and yield. (The latter two also apply during the processing stage).

- The raw materials are perishable: this applies to finished goods also, although to a lesser extent.

- Inventory and overproduction are used to combat demand fluctuation, rather than collaborating on meeting demand.

- The retailer is the dominant party- over $50 \%$ of the market is controlled by five retailers.

Similar to most industries, there is a shift towards a greater variety of end products, with consequently smaller batch sizes and more frequent delivery. The retailers are instrumental in actively promoting these changes along the supply chain. Although each of the players commit to yearly plans, there is little interaction until 'call-off' orders are placed, which generally occurs weekly with monthly horizons. An analysis of the co-ordinated GRAI grid yielded the following inconsistencies or problems: 
- The topmost decision centre in each case had a horizon of one year. This indicated that no strategic emphasis had been placed on the interrelationships developed, although each company had been working together for several years.

- The seasonal sales forecast developed by the retailer is not fully exploited. The processing plant develops a monthly production schedule, with the result that the supplier is effectively blind to this information.

- The 'call-off' procedure is carried out by the processing plant with a frequency greater than once per week (with a monthly horizon); however, the supplier plans harvests weekly, so orders may not be taken into account until the following weekly harvest meeting.

- Forecasting figures for capacity scheduling is used at the expense of actual feedback information; this is true for the retailer and processor, with the result that the supplier is forced to cope with inaccuracy.

- Logistics (especially transport) is planned independently.

Therefore, along with recommending the 'pooling' of forecasting information amongst all parties, the analysis indicated that the processing plant's production plan should be aligned with the promotional plan of the retailer. The logistics issue is also important- the delivery schedule of the retailing distribution centre should provide the basis for the call-off orders to the processing plant.

\subsection{Textile Industry}

The companies examined are involved in the manufacture and retail of formal fashion clothing; the example chosen showed the manufacture of suits. The supplier supplies cloth to the manufacturer; this is then cut, sewn and pressed into the requisite garment before being sent to the retailer. The following statements are representative:

- The demand pattern is highly seasonal (there are two 'fashion seasons' per annum): the lead time to manufacture of a garment is typically sixty weeks, with $90 \%$ of customer (retail) orders placed in an 8-10 week window.

- The Manufacturer is the focus of the network, since the product is a branded fashion item.

- The supply chain should be 'agile'; i.e. quick to respond to demand in order to minimise inventory and wastage. Practises such as bulk ordering (to avail of discounts) and extensive forecasting with a tradition of associating cost with production efficiency tend to distort the already seasonal demand pattern.

- Each company involved tends towards maintaining sizeable inventories, although recognising that these should be minimised.

By, creating grids for the supply chain, some problems were highlighted. The manufacturer created a sales forecast which used the previous years customer orders, plus some feedback from retailers who saw 'prototype' garments. This sales forecast is used to create the production budget and send bulk orders to the 
product line up, or latest fashion news), which consequently pressurises the supplier. This is accentuated by the fact that the supplier worked solely to sales orders, and scheduled production in 'buckets' with work scheduled on a 'first in' basis without prioritising delivery due dates. The supplier thus had large inventories of raw materials to cope with demand, again worsened by the fact that the supplier is linked to three other companies in order to make the cloth. A problem common to all of the firms is the tendency to have decision centres with equivalent periods and horizons. This is a typical reaction to a seasonal demand pattern, but results in a plan which, once implemented, cannot be corrected. The 'social system' then predominates as a form of interaction, with individuals in the various companies bypassing 'standard' systems to meet demand.

Some encountered problems were:

- Due to the large lead time from order to delivery, the approach favoured by the retailer is to place an initial bulk order for a percentage of anticipated demand (e.g. 66\%), and follow this with a further reorder as and when required, for the remainder of the season. This adds to the large glut of orders, contributing to the problem it tries to preempt.

- The manufacturer and supplier both have a decision structure which goes from a node with a sizeable horizon ( $\mathrm{P} \geq 6$ months) to a much more frequent one $(\mathrm{P}=2$ weeks, or 1 week in the case of the supplier). This places a large burden on the decision node further down, which must use its limited powers (due to the hierarchy of decision nodes) to conform to a seasonal plan. An intermediate node ( $\mathrm{P}=1$ month) could be established in both companies, and coordinate material transfer at a level between bulk orders and call-off's from inventory.

- There needs to be improved visibility throughout the chain- this must be reinforced by a review of the retail ordering procedure. A common, updated forecast should be created, so that every party has an idea of how material flow needs to be synchronised. This needs to be achieved by reducing lead times, and eliminating bulk orders.

\subsection{Consumer Electronics}

The companies here are involved in the manufacture and retailing of electronic goods (predominantly television sets). As in the case of the textile industry, demand is influenced by brandnames, which empowers the manufacturers (in most cases, large multinational companies) in determining the 'atmosphere' of the interactions. Strategic ownership has been practised by many manufacturers, thereby gaining insights into the intent of firms in the network, and reducing the risks of investment in infrastructural links to other firms. Retail demand forecasts are influenced not only by anticipated consumer demand, but by the 'promotion schedule' of the manufacturer. This enables the retailer to have a vision of the product range on offer, and is of benefit to the manufacturing firm in that the annual retail demand forecast is subject to its influence. The same relationship does not exist between manufacturer and supplier, where the supplier provides goods subject to manufacturing forecasts (updated quarterly) and firm orders 
(updated weekly). The supplier perception tends towards creating inventory to cope with deviations from the forecasted demand. The ensuing points reflect on the model further:

- In most cases, the annual plan is not subject to revision. While this could indicate that forecasts are sufficiently accurate, it places the onus on the monthly procedures of planning and purchasing to meet annual targets.

- The logistics movements of all parties are planned independently. This has the effect of increasing both pipeline inventory and the amount of stock held in various distribution centres. The most rapid distribution system belongs to the supplier, again reflecting the nature of the response to manufacturing orders.

\section{CONCLUSIONS \& FUTURE RESEARCH}

This paper has cited both the synchronisation of decision making processes, and the subsequent flow of information within a network, as influential to its overall effectiveness. The modifications to the generic GRAI grid are described, as is the interview format. Three industries, each containing three vertically linked companies were approached and modelled, and the findings later reviewed. The problems highlighted point to the ability of this analytical approach to model decision and information flows. The approach is also less complex and correspondingly simpler to use than, for example, industrial dynamics.

The research, while encouraging, is exploratory; further work will address some of the undeveloped issues that were raised. These include an analysis of horizontal linkages within a network, and the effect of multiple relationships on the coordination of decision making (as opposed to the individual network 'streams' over which this paper deliberates). It is also envisaged that the recommendations suggested here will be implemented in some of the firms, and the effects assessed.

\section{REFERENCES}

Doumeingts, G. (1985), How to decentralise decisions through GRAI models in production management. Computers in Industry, No. 6 North Holland Publishing.

Downey, S. Ridgeway, K. and Pun, L. (1989) The use of the GRAI technique in a small manufacturing company. Fourth International Conference on Computer Aided Production Engineering, Cape 4.

Elg, U. and Johansson, U. (1996) Networking where national boundaries dissolve. European Journal of Marketing, Vol. 30 No. 2, pp. 61-74

Ellram, L. and Cooper, M (1993) Characteristics of Supply Chain Management and the implications for purchasing and logistics strategy. International Journal of Operations and Production Management, Vol. 4 No. 2, pp. 1-10.

Hakansson, H. (1982) International Marketing and Purchasing of Industrial Goods: An Interaction Approach, Wiley.

Moller, C. Riis, J.O. and Hansen, M. (1998) Interorganisational network classification- A framework for studying networks from a manufacturing 
perspective. IFIP WG 5.7 Working Conference 1998: Strategic Management of the Manufacturing Value Chain.

New, S.J. (1996) A Framework for analysing supply chain improvement. International Journal of Operations and Production Management, Vol. 16 No. 4, pp. 19-34.

O'Neill, H. and Sackett, P. (1994) The Extended Manufacturing Enterprise Paradigm. Management Decision, Vol. 2 No.8 pp. 42-49.

Rich, N. and Hines, P. (1997) Supply-chain management and time-based competition: the role of the supplier association. International Journal of Physical distribution and Logistics Management, Vol. 27 No. 3/4 pp. 210-225.

Thorelli, H.B. and Cavusgil, S.T. (1990) International Marketing Strategy, Pergammon Press.

Towill, D.R. (1995) Industrial dynamics modelling of supply chains. International Journal of Physical distribution and Logistics Management, Vol. 26 No. 2 pp. 23-42.

Williamson, O.E. (1979) Markets and Hierarchies, The Free Press.

\section{BIOGRAPHY}

Fiachra Coll (M. Eng.) is a Researcher in the University of Strathclyde.

Allan Carrie is Professor of Manufacturing Systems at the University of Strathclyde. A Chartered Engineer, he is affiliated to the IEE, RSA, IEEE and IOM, and has been a panel member of UK Technology Foresight program. His main interests are in computer aided production management, and technology management.

Dr. Umit Bititci is the Director of the Centre for Strategic Manufacturing and is a Senior Lecturer at the University of Strathclyde. Umit is actively involved in researching business operations and information strategy in addition to performance measurement and management.

Dr. Jacques H. Trienekens has been an Assistant Professor at Wageningen University in the Netherlands since 1991. Prior to this he worked as a consultant in public health organisations, and as a Lecturer of information systems in various Institutes of Higher Education. He is currently researching logistics and the impact of information systems on supply chain management.

Hans-Henrik Hvolby (Ph.D.) is an Associate Professor at the Department of Production in the University of Aalborg, Denmark. Involved in numerous research projects in collaboration with industry, his research areas concentrate on production planning and control and order management and information systems.

Alison Reid is a final year Manufacturing Sciences \& Engineering (M. Eng.) student at the University of Strathclyde. 